\title{
Proofs in Mathematics Education: Expectations and Reality
}

\author{
Brian Frasier $^{1} \&$ Regina Panasuk ${ }^{2, *}$ \\ ${ }^{1}$ Merrimack College, North Andover, Massachusetts, United States \\ ${ }^{2}$ University of Massachusetts - Lowell, Lowell, Massachusetts, United States \\ *Corresponding author: Graduate School of Education, O'Leary Library 526, University of Massachusetts, Lowell, \\ Massachusetts, United States. Tel: 1-978-934-4616. E-mail: Regina_Panasuk@uml.edu
}

Received: August 2, 2013

Accepted: September 17, 2013

Online Published: October 6, 2013

doi:10.5430/jct.v2n2p76

URL: http://dx.doi.org/10.5430/jct.v2n2p76

\begin{abstract}
This article describes a part of a large scale study which helped to gain understanding of the high school mathematics teachers' belief about proof. There is obvious disconnect between general beliefs and high school teachers' conceptions about proof as central element of mathematics and mathematics education. A total of 374 mathematics teachers from one of the New England states, USA, participated in an on-line comprehensive original survey designed specifically for this study. We report on several units of analysis including teachers' beliefs about proof as a vehicle for developing reasoning skills, proof as a central to learning mathematics, and classroom time spent on proof with different categories of students, and offer some recommendations for teacher professional development and suggestions for further research.
\end{abstract}

Keywords: proof in mathematics education; mathematics teachers beliefs

\section{Introduction}

If we are serious about improving mathematics education, we have to clearly define what we want the young generation to show after they have forgotten what they have learned in school (Einstein, n.d.). We should be concerned whether school learning provides all students with the opportunity to develop reasoning skills and abstract thinking. Abstract thinking is characterized by the ability to construct generalizations of experiences with objects into ideas or concepts that exist in some degree of separation from the physical world that triggered those ideas or concepts. This ability enables one to solve problems, reason deductively, and to develop higher order cognitive skills, e.g., analysis, synthesis, evaluation (Bloom et al., 1956). Abstract thinking abilities also enable students to build a "fluid and crystallized intelligence" (Horn \& Cattell, 1966, p. 256) and make use of that intelligence in complex ways outside of school.

Recently the Common Core (2011) in the Standards for Mathematical Practice has taken a strong position stating that the development of abstract thinking should be an integral part of learning mathematics, and is essential to the development of conceptual understanding of mathematics. The Common Core advocates that students must be given ample opportunities to reason abstractly and quantitatively, construct viable arguments and critique the reasoning of others, use appropriate tools strategically, attend to precision, look for and make use of structure, and express regularity in repeated reasoning. It is assumed that by partaking in these mathematical practices students are enabled to develop their abstract thinking (CCMMS, 2011).

Mathematical proof, as a structural element of mathematics, is one of the most obvious medium a teacher could use to help students develop abstract thinking. Historically, the introduction of deductive proofs within an axiomatic system transformed mathematics from what Kline (1972) referred to as merely "a tool in the form of disconnected, simple rules which answered questions arising in daily life" (p.22), into the theoretical discipline that mathematics is today. Proof in mathematics represents a quintessence of abstract thinking as it is used to verify, justify, and systemize mathematical knowledge. The experience of working with proof is undoubtedly a fundamental element of both the discipline itself and the learning of mathematics.

Under this premise, we turn to the reality of the K-12 classrooms. Many scholars and researchers (e.g., Jones, 1997; Martin \& Harel, 1989; Goetting, 1995; Simon \& Blume, 1996; Harel \& Sowder, 1998; Knuth, 1999; Seldon \& 
Seldon, 2003; Vargese, 2007; Stylianides \& Stylianides, 2009) observed a significant loss of opportunity to use proof in mathematics classrooms, and investigated why teachers are presenting students with little proof experiences (if any) in K-12 mathematics curricula. Thus, examining practicing mathematics teachers' beliefs and perceptions about proof in mathematics as discipline and as pedagogical tool to promote students' development of abstract thinking seems justified.

\section{Background}

It is well known fact that the National Council of Teachers of Mathematics (NCTM, 1989) has been encouraging mathematics teachers to facilitate students' development of abstract thinking abilities for decades. In the 1989 Curriculum and Evaluation Standards for School Mathematics, NCTM presented standards including "mathematics as reasoning" to move away from a perspective that mathematics learning should be dominated by rote memorization of facts and formulae and progress toward the idea that mathematics was about concepts, procedures, and reasoning. In 2000, NCTM emphasized that mathematical proof is intrinsically related to reasoning in general, and in mathematics in particular, and specifically named "proof and reasoning" as one of the process standards. The NCTM also stressed the notion of conceptual understanding as a hallmark of abstract thinking. As noted above, Common Core Standards for Mathematical Practice (CCMSS, 2010) maintains a steadfast support for the notion that abstract thinking in mathematics is a critical component of mathematics learning.

Individual scholars have also stressed the necessity building students' abstract thinking abilities. Nickerson (1986) contended that, "the ability to reason effectively is no less important to success in school, in the workplace, and in life in general than reading, writing, and arithmetic" (p. 343). Wu (1996), Sowder and Harel (1998), and Perrin (2009) have specifically encouraged to focus on proofs in mathematics classrooms to facilitate students' development of abstract reasoning skills. They believe that being able to reason effectively is not only essential to learning mathematics, it is essential to all aspects of life inside and outside of school. Wu (1996) pointed out that by learning about proofs students acquire the ability to "listen to national debate and make up their minds about knotty issues such as the national deficit and the environment” (p.224).

Given the importance of proof in mathematics and mathematic curricula, Knuth (2002) studied 16 in-service secondary school mathematics teachers' conceptions about proofs and revealed that, "the majority of teachers identified the development of logical thinking or reasoning skills as a primary role proof plays in secondary school mathematics" (p.78). However, "the majority of teachers did not consider proof to be a central idea throughout secondary school mathematics, questioning its appropriateness for all students" (p.73). More specifically, Knuth documented that for many teachers, "proof seemed to be an appropriate idea for only those students enrolled in advanced mathematics classes and those students who will most likely be pursuing mathematics-related majors in college" (p.73). Frasier (2010) found these conceptions to be widespread among a large sample of in-service high school mathematics teachers. This article is focused on a subset of the data in Frasier (2010).

\section{Method}

\subsection{Instrument}

To measure the extent to which the conceptions identified by Knuth (2002) were representative of a larger population of in-service secondary mathematics teachers, an original online survey using SurveyMonkey ${ }^{\mathrm{TM}}$ software was created. This survey was designed to conduct a comprehensive investigation into different factors that reflected secondary teachers' conceptions of and practices with proof, and provided data for several units of analysis including conceptions about proof as a vehicle for developing reasoning skills, proof as a central element to learning mathematics, and classroom time spent on proof with different categories of students.

Most of the items were presented as a five point Likert Scale where possible responses included strongly agree, agree, neither agree nor disagree, disagree and strongly disagree. There were also items designed as a checklist or drop-down menu format, as well as positively and negatively oriented items to minimize different sources of bias. To insure that certain intricacies related to teachers' beliefs and practices with proof could be measured, different choices of words were used to present the items rooted in the same idea.

To determine whether in-service secondary mathematics teachers were reserving proof experiences from lower level students, the participants were asked to approximate the percentage of class time they spent on proof with four different mathematics classes/levels. Dropdown menus were used that allowed participants to select $0 \%$ through 100\% 
at $5 \%$ intervals. Participating teachers were also presented with the following checklist of potential reasons that would deter them from using proof in their teaching and asked to select all that applied (1) my textbooks, (2) standardized testing, (3) the ability level of students that I teach, (4) the grade level of the students that I teach, (5) the courses that I teach, (6) lack of parental cooperation, (7) school resources, (8) state standards, (9) my fellow teachers' attitudes toward proof, (10) my administrators, (11) my own mathematical knowledge, (12) my own pedagogical knowledge. Lastly, participants were asked to approximate the percentage of students that they believed to be intellectually capable of understanding mathematical proof. A drop-down menu was used from $0 \%$ through $100 \%$ again in $5 \%$ intervals.

Demographic data was solicited from the state as well as from the survey participants for the purposes of determining the representativeness of the sample compared to the state population. To ensure content validity of the survey items, several revisions incorporated the feedback provided by experts in mathematics education and in survey design. To assure that survey items were clearly articulated, a small pilot study was conducted. Pilot participants were asked to comment on the following aspects of the survey upon its completion (1) functionality, (2) aesthetic design, (3) length of time required to complete the survey, (4) item content, and (5) miscellaneous comments. Pilot study participant data were not included in the results of this study.

To establish reliability of the instrument, a Cronbach's alpha test on standardized items was run and generated a .91 value, which suggests very high reliability. A factor analysis was used to determine that the survey instrument possessed reasonable construct validity.

\subsection{Participants}

Three-hundred and seventy-four high school mathematics teachers from one of the New England states, USA, participated in this study by taking the online survey. Two-hundred and nine of the participants responded to every item on the survey. The remaining 165 teachers provided differing levels of partial data, which was used when statistically appropriate. A chi square test determined that the sample was not significantly different than the statewide population of secondary mathematics teachers with regard to gender, race, or age $(\mathrm{p}<.05)$.

Given that $11 \%$ of the 3,334 public high school mathematics teachers in the state participated in this study, in demographic proportions similar to the overall state population, generalizing from the sample to the overall state population of high school mathematics teachers seems reasonable and justified. These data provide a foundational basis for eventually generalizing to the national or multinational population of secondary mathematics teachers, though more studies are needed.

\section{Results}

\subsection{The Units of Analysis}

While there were several units of analysis of data, this paper reports on i). teachers' beliefs about proof as a vehicle for developing reasoning skills (see Table 1), ii). proof as a central to learning mathematics (see Table 2), and iii). classroom time spent on proof with different categories of students (see Table 3, Figure 1).

\subsubsection{Teachers' Perceptions about Proof as a Vehicle for Developing Reasoning Skills}

Almost all of the participating teachers believed that helping students develop logical reasoning ability was a primary goal of mathematics education (94.9\%), and that proofs could be used to help students develop logical thinking ability (93\%). These data strongly support Knuth's (2002) findings and assertions. Since 83.3\% of the teachers claimed that learning about proof helped them develop their own logical thinking abilities (see Table 1, item 4), we speculate that teachers' own experience with proof affected their responses in items 1, 2, and 3 (see Table 1). 
Table 1: Proof as a Vehicle for Reasoning

\begin{tabular}{|c|c|c|c|c|c|}
\hline Item & $\begin{array}{l}\text { Strongly } \\
\text { Agree }\end{array}$ & Agree & Neither & Disagree & $\begin{array}{l}\text { Strongly } \\
\text { Disagree }\end{array}$ \\
\hline $\begin{array}{l}\text { 1. Helping students develop logical } \\
\text { thinking ability is a primary goal of } \\
\text { mathematics education }\end{array}$ & $48.9 \%$ & $46.0 \%$ & $4.6 \%$ & $0.5 \%$ & $0.0 \%$ \\
\hline $\begin{array}{l}\text { 2. Proofs can be used to help students } \\
\text { develop logical thinking abilities }\end{array}$ & $34.7 \%$ & $58.3 \%$ & $4.8 \%$ & $1.9 \%$ & $0.3 \%$ \\
\hline $\begin{array}{l}\text { 3. Teachers can do little to help students } \\
\text { develop logical thinking abilities }\end{array}$ & $1.6 \%$ & $2.2 \%$ & $5.6 \%$ & $55.4 \%$ & $35.2 \%$ \\
\hline $\begin{array}{l}\text { 4. Learning about proof has helped me } \\
\text { develop logical thinking abilities }\end{array}$ & $35.2 \%$ & $48.1 \%$ & $11.7 \%$ & $2.6 \%$ & $2.3 \%$ \\
\hline
\end{tabular}

\subsubsection{Proof as a Central to Learning Mathematics}

About 54\% of the teachers thought that proof is one of the most important elements in mathematics, and nearly half (47.3\%) thought that it is possible to understand the nature of mathematical knowledge without proof (see Table 2). A remarkably low number of teachers (48.9\%) had a view that removing proof from mathematics would create an entirely different subject and only $48.9 \%$ agreed that proof was one of the most important elements in mathematics education. A significant positive correlation (Spearman's rho = .6, $\mathrm{p}<.01 ; \mathrm{N}=345$ ) was found between the item 1 (Proof as one of the most important elements in mathematics) and the item 4 (Proof as one of the most important elements in mathematics education). In other words, a teacher who considered proof one of the most important elements in mathematics was likely to consider proof to be one of the most important elements in mathematics education.

Again, these data support Knuth's (2002) observation that some teachers did not see proof to be a central idea throughout secondary school mathematics, nor central to the discipline of mathematics itself. The nearly unanimous consensus that proof is an essential element of both the discipline of mathematics and of school mathematics that exists among scholars and mathematicians was not found within the sample.

Table 2: Proof as a Central Idea throughout Secondary School Mathematics

\begin{tabular}{|c|c|c|c|c|c|}
\hline Item & $\begin{array}{l}\text { Strongly } \\
\text { Agree }\end{array}$ & Agree & Neither & Disagree & $\begin{array}{l}\text { Strongly } \\
\text { Disagree }\end{array}$ \\
\hline $\begin{array}{l}\text { 1. Proof is one of the most important elements in } \\
\text { mathematics }\end{array}$ & $13.8 \%$ & $40.1 \%$ & $26.9 \%$ & $17.1 \%$ & $2.1 \%$ \\
\hline $\begin{array}{l}\text { 2. It is possible to understand the nature of } \\
\text { mathematical knowledge without proof }\end{array}$ & $8.7 \%$ & $38.6 \%$ & $24.1 \%$ & $23.8 \%$ & $4.8 \%$ \\
\hline $\begin{array}{l}\text { 3. If proofs were removed from mathematics the } \\
\text { subject would be entirely different }\end{array}$ & $13.1 \%$ & $35.8 \%$ & $32.8 \%$ & $16.3 \%$ & $2.0 \%$ \\
\hline $\begin{array}{l}\text { 4. Proof is one of the most important elements in } \\
\text { mathematics education }\end{array}$ & $11.9 \%$ & $39.6 \%$ & $30.7 \%$ & $14.3 \%$ & $3.5 \%$ \\
\hline $\begin{array}{l}\text { 5. Proof is important for upper-level high school } \\
\text { mathematics students }\end{array}$ & $51.8 \%$ & $39.4 \%$ & $5.6 \%$ & $3.1 \%$ & $0 \%$ \\
\hline $\begin{array}{l}\text { 6. Proof is important for mid-level high school } \\
\text { mathematics students }\end{array}$ & $12.4 \%$ & $61.7 \%$ & $17.7 \%$ & $8.2 \%$ & $0 \%$ \\
\hline $\begin{array}{l}\text { 7. Proof is important for low-level high school } \\
\text { mathematics students }\end{array}$ & $5.9 \%$ & $33.9 \%$ & $21 \%$ & $30.8 \%$ & $7.9 \%$ \\
\hline
\end{tabular}


The teachers showed substantially different conceptions about the importance of proof in relation to different abilities of students. Clearly, the majority of the teachers (about 91\%) believed that proof is essential for upper-level mathematics students, a somewhat less number of the teachers (74\%) believed that that proof is important for mid-level students, and a minority of the teachers (39\%) agreed that proof is important for lower-level students. These data strongly support Knuth's (2002) assertion that many teachers questioned the appropriateness of proof for all students.

\subsubsection{Classroom Time Spent on Proof with Different Categories of Students}

Teachers reported that the amount of class time that they would spend on proof varied with respect to both the particular mathematical subject being taught and the students' academic level. The teachers responses related to the approximate percentage of class-time they would spend on proof in four different course types, i) upper level geometry, ii) lower level geometry, iii) upper level algebra, and iv) lower level algebra, are shown in the Figure 1, which illustrates the responses displayed in box and whisker plots.

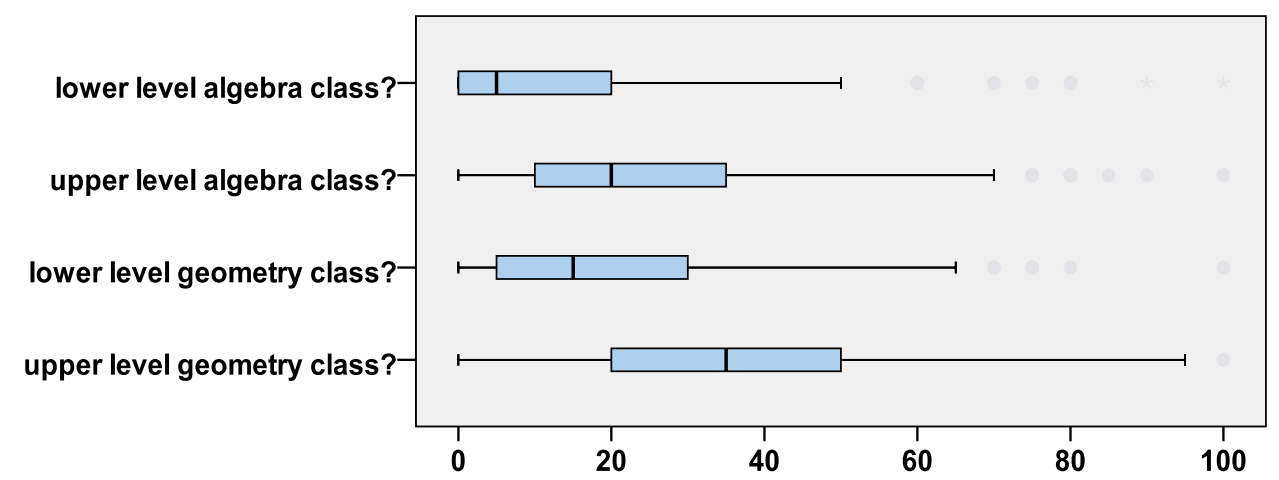

Figure 1: Percentage of Class Time the Teachers Reported Spending on Proof in Different Sub-Disciplines/Levels

Mean percent of the class-time (see Table 3) and sample t-tests (see Table 4) were used to compare the amount of class time spent on proof in upper versus lower level mathematics classes (with the subjects held constant) and the amount of class time spent on proof in geometry versus algebra (with the academic level held constant). The results of the t-tests indicated that there is a significant difference $(\mathrm{p}<.001)$ in the amount of class time spent in both types of comparison, students' academic level and the particular mathematical subject being taught.

On average, teachers reported that they would spend twice as much time on proof in upper levels as they would spend in lower levels (independent of mathematical subject), which is consistent with the majority teachers' conception that proof is more important to the upper level students. The responses also suggest that the teachers would spend $60 \%$ more time on proof in geometry than in algebra (regardless the students' academic level).

Table 3: Mean Percent Class-time Spent on Proof in Different Sub-Disciplines/Levels

\begin{tabular}{llllc}
\hline Class-time spent in ... & Mean & N & Std. Deviation & St Error Mean \\
\hline 1. Upper Level Geometry & $38.70 \%$ & 326 & 22.95 & 1.27 \\
2. Upper Level Algebra & $24.62 \%$ & 326 & 21.71 & 1.20 \\
3. Lower Level Geometry & $19.64 \%$ & 330 & 18.09 & 1.00 \\
4. Lower Level Algebra & $12.11 \%$ & 330 & 16.41 & .90 \\
\hline
\end{tabular}


Table 4: Differences between Mean Percent Class-time in Different Sub-Disciplines/Levels

\begin{tabular}{|c|c|c|c|c|c|c|c|c|}
\hline \multirow[b]{2}{*}{$\begin{array}{l}\text { Groups } \\
\text { Compared } \\
\end{array}$} & \multirow[b]{2}{*}{ Mean } & \multicolumn{6}{|c|}{$\begin{array}{l}\text { 95\% Confidence } \\
\text { Interval of the } \\
\text { Difference }\end{array}$} & \multirow[b]{2}{*}{$\begin{array}{l}\text { Significance } \\
\text { (2-tailed) }\end{array}$} \\
\hline & & $\begin{array}{l}\text { Std. } \\
\text { Deviation } \\
\end{array}$ & $\begin{array}{l}\text { Std.Error } \\
\text { Mean } \\
\end{array}$ & Lower & Upper & $\mathrm{t}$ & df & \\
\hline $\begin{array}{l}\text { 1. Upper Geometry } \\
\text { Upper Algebra }\end{array}$ & 14.080 & 19.117 & 1.059 & 11.997 & 16.163 & 13.298 & 325 & .000 \\
\hline $\begin{array}{l}\text { 2. Lower Geometry } \\
\text { Lower Algebra }\end{array}$ & 7.530 & 14.640 & .806 & 5.945 & 9.116 & 9.344 & 329 & .000 \\
\hline $\begin{array}{l}\text { 3. Upper Geometry } \\
\text { Lower Geometry }\end{array}$ & 18.811 & 17.186 & .949 & 16.944 & 20.678 & 9.823 & 327 & .000 \\
\hline $\begin{array}{l}\text { 4. Upper Algebra } \\
\text { Lower Algebra }\end{array}$ & 12.240 & 13.794 & .751 & 10.762 & 13.718 & 16.29 & 336 & .000 \\
\hline
\end{tabular}

A significant difference $(\mathrm{p}<.001)$ was also observed between the number of teachers that reported spending $0 \%$ of class time on proof in each of the course types. Three percent of teachers claimed that they would not spend any time on proof in an upper level geometry course, whereas $15 \%$ claimed the same for lower level geometry, $13 \%$ for upper level algebra, and 33\% for lower level algebra. Therefore, participating teachers were 3-5 times more likely not to use proof at all in their teaching of lower level mathematics classes as compared to upper level classes.

Two compound variables were used to measure the relationship between teachers' conceptions about proof and their classroom practices. The first compound variable, named 'importance', was used to reflect teachers' beliefs of the importance of proof in mathematics and in mathematics education at all academic levels, and the second, called 'classtime', was used to reflect how much class time a teacher would spend on proof. Six items in all were combined to create the 'importance' variable and four items were combined to create 'classtime' variable. A high value for the 'importance' variable would mean that the teacher believed mathematical proof is important to mathematics and mathematics education, and a high value for 'classtime' indicated that a teacher spent a lot of class time teaching about proof. A positive and significant correlation (Pearson's $\mathrm{r}=.4, \mathrm{p}<.01$; $\mathrm{df}=277$ ) was found between 'importance' and 'classtime'. As one might expect, teachers who believe that proof is important to mathematics and mathematics education (at all levels) were more likely to spend more time on proof in their teaching than those teachers who did not think that proof is important.

\subsubsection{What Discouraged Teachers from Using Proof}

The analysis of data indicates that teachers in the sample were somehow reserving proof experiences from their students. To investigate the motives the teachers would reserve proof experiences from their students, the participants were presented with a dozen of potential reasons to choose from (see Figure 2). 


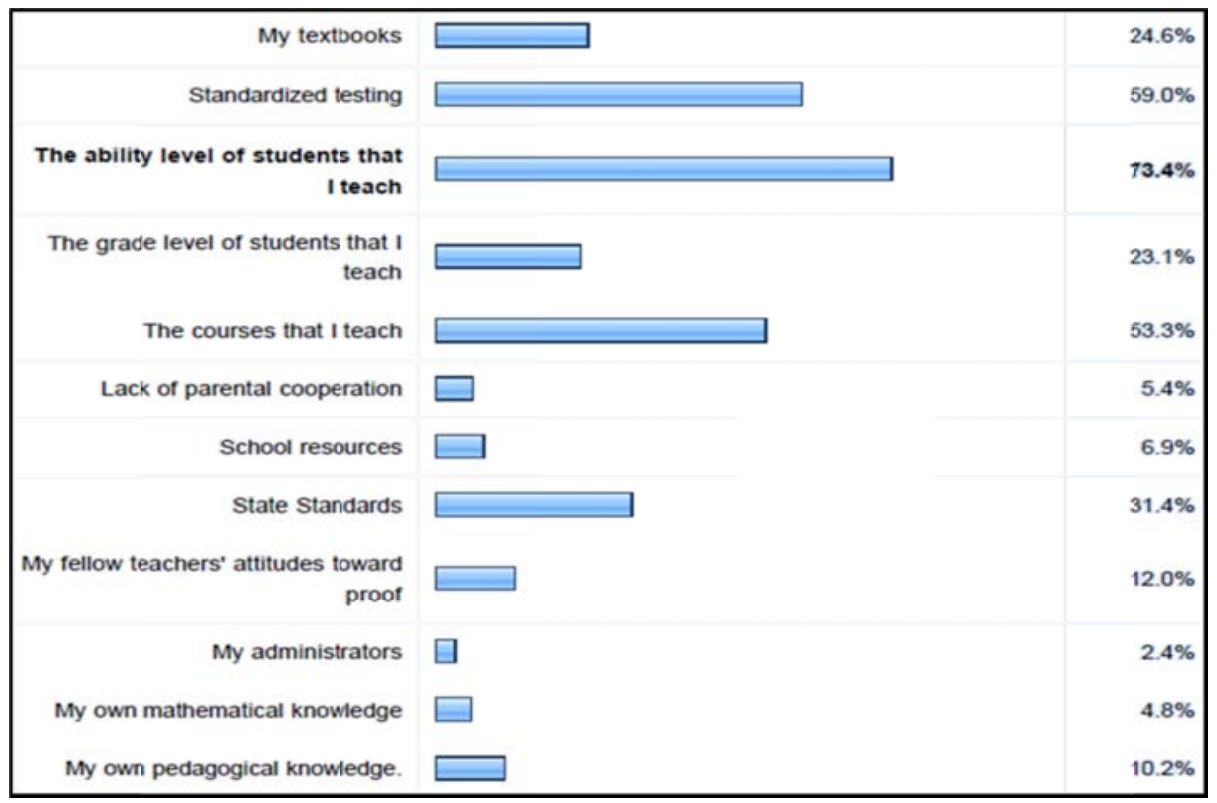

Figure 2: The Percentage of Teachers That Felt Discouraged from Using Proof in Their Teaching

Ninety-four percent of 325 teachers $\left(N_{\text {total }}=374\right)$ reported on at least one reason that discouraged them from using proof in their teaching. The most frequently selected item was, 'the ability level of students that I teach' (73.8\%). Given the percentage of teachers (72\%) who reported that proof is more important for upper level mathematics students than for lower level students, we hypothesize that nearly three quarters of the participants did not use proof in their teaching because the majority of their students were at the lower level. The second most frequently selected disincentive (59\%) was 'standardized testing,' which is one of the major criteria for assessing student performance and teacher effectiveness. Since the standardized tests rarely include items related to proof, the teachers might have felt justified not to focus on proof, but rather on the other curriculum domains that were more representative of standardize test items.

The third most frequently (53.3\%) selected disincentive selected was the item 'The courses that I teach'. Apparently, this group of teachers held the view that proofs are the element of geometry courses exclusively. It is interesting to note that the percentage of teachers (53.3\%) who believed that the courses they taught discouraged them from using proof was consistent with the cumulative percentage of teachers (see Table 2, item 1, 46.1\%,) who did not agree that proof was an essential element in the discipline of mathematics.

Participating teachers were also asked to approximate the percentage of their students who were intellectually capable of understanding mathematical proof (see Figure 3). The box and whisker plot illustrates the sample of participating teachers broken into quartiles. The mean response showed that $70 \%$ of students (with a standard deviation of 22\%) were identified as intellectually capable of understanding mathematical proof. The remaining $30 \%$ of the student population would probably be identified as the lower level students.

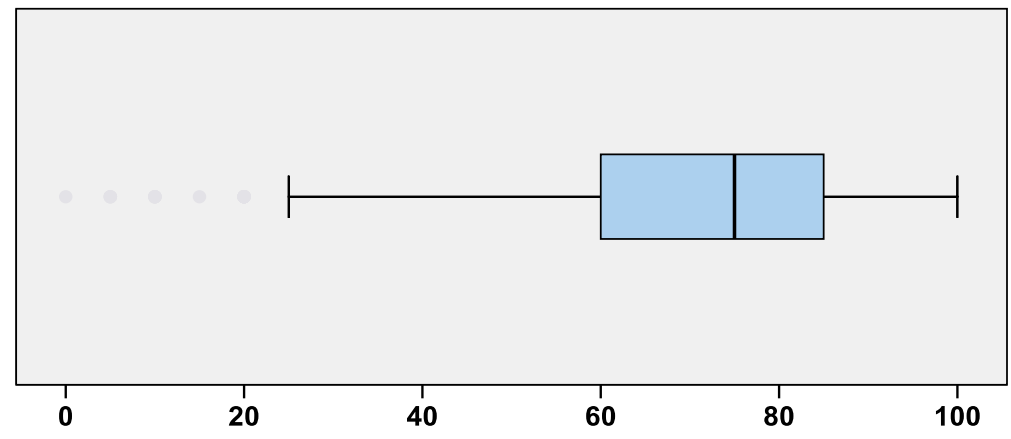

Figure 3: The Percentage of All Students That Teachers Believed to be Intellectually Capable of Understanding Mathematical Proof 
In summary, the presented data strongly supports Knuth's (2002) observations of in-service secondary school mathematic teachers' conceptions of proof in mathematics, and provides a quantitative measure of the extent to which these conceptions apply to a larger population of in-service teachers. The key findings included (1) about $90 \%$ of the participants thought proof was a means to help students develop logical reasoning ability; (2) only half of the participants saw proof as central element of mathematics and mathematics education, (3) three-quarters of the teachers reported reserving proof experiences from lower level mathematics students, a practice that is likely related to the belief that on average more than a quarter of their students were perceived to be intellectually incapable of understanding mathematical proof. These startling findings show how teachers' beliefs about proof in mathematics and mathematics education are often inconsistent and, at times, contradict to their own pedagogical beliefs about the goals of mathematics education.

\section{Discussion}

While there has been no shortage in warning that proof has been likely underused by mathematics teachers, this study offers quantitative evidence that the quality of secondary school mathematics education may be jeopardized. Knuth's (2002) study gave the mathematics education community reason to be concerned that certain beliefs and perceptions about proof in secondary school mathematics were likely to exist within the population of in-service secondary school mathematics teachers. This study gives the mathematics education community reason to be alarmed that these beliefs and perceptions appear to be widespread. Here we offer our interpretation of the data on teachers' thinking and decision making related to reserving proof experiences from some of their students, and possible course of action to enact positive change on the current situation.

Teachers in the study reported that nearly a third of all students are intellectually incapable of understanding proof. We question whether the teachers indeed believed that such a large portion of students are cognitively inhibited from at least comprehending (Bloom et al., 1956) a mathematical proof, or there may be another dimension such as the amount of material the teachers were expected to teach in a given classroom time. If so, and it is likely that the teachers faced challenges working with students of lower academic level, it would not be possible to bring these students up to proficient student's level of understanding of mathematical proof. However, even this more nuanced teachers' position is rooted in serious misconceptions of the importance of proof in mathematics education. Half of the study's participants did not agree that proof is an essential element of mathematics, or believed that proof was necessary to understand the nature of mathematics, or thought that mathematics would be fundamentally altered if proof were removed from the mathematical system. This is an obvious disconnect from the conceptions of professional mathematicians who believe that proof is an essential element of mathematics. While it is clear that helping students to comprehend mathematical proof at a conceptual level would take a substantial amount of effort and time, teaching mathematics without proof, or even deemphasizing proof could only result in a distorted view of the discipline and undervaluing the importance of abstract reasoning skills. Thus, it seems noteworthy to speculate why $50 \%$ of the secondary mathematics teachers believed there is even an option as to whether teach mathematics without proof. If these teachers believed that proof is not an essential element of mathematics curriculum, then what could have been their perception of what proof is. Our analysis of the current Geometry textbooks used in the classrooms (we omit the reference to the publishing companies) with the notable exception for the textbook published by Center for Mathematics Education Project (CMEP, 2012), shows that the proof is treated more as a topic rather than as an integral ingredient of mathematics. Teachers who are compelled to use such textbooks and who have no solid training in the history and philosophy of mathematics are likely to adopt such view. We claim that reducing proof to a topic undermines its value as an essential element of mathematics and holds back an opportunity to facilitate the development of logical reasoning and abstract thinking in students.

A vast majority (90\%) of the participating teachers reported that the development of logical thinking was a primary goal of mathematics education, and that proofs are a viable vehicle to accomplish the goal. It was unexpected that $61 \%$ of the participating teachers did not believe that proofs were important for lower level students. These teachers indicated that on average they spent half the time on proof with lower level students as they would with their upper level students.

In our view, exposing mid-level and upper-level students to proof in mathematics while depriving lower level students from proof experiences in secondary mathematics classes poses a serious ethical problem and creates obvious inequity. Not only this deprivation would influence lower level students to perceive mathematics as a disconnected set of random rules and procedures with little practical implication in today's world outside the classroom, but it would deny them an opportunity to develop their logical reasoning and abstract thinking. Moreover, 
it seems logical to assume that for lower level mathematics students who are least likely to use the content specific skills learned in secondary mathematics (e.g., quadratic formula, trigonometric functions), it would make sense to focus on the development of general reasoning skills (e.g., building an argument, following logic, justifying the process or steps).

\section{Conclusion}

In light of the study's findings we urge to focus pre-service teacher preparation and in-service teacher professional development on the efforts towards educating all teachers about the role and the significance of proof in mathematics. Such education will undoubtedly require specific attention to the historical and philosophical underpinnings of the nature of proof in mathematics. It will also require attention to the nature of mathematics as an axiomatic system not only limited to geometry (e.g., Peano's axiomatic system of arithmetic). If teachers avoid using proof in their teaching because they don't know or are not confident with the proofs in sub-divisions of mathematics (e.g., algebra, trigonometry, etc.), a consistent and systematic support must be provided to help the teachers learn and appreciate proofs involving elementary algebra concepts (e.g., the product of an even and an odd number is even). Teachers must have the opportunity to learn that not all proofs are confined to geometry, and not all proofs are necessarily too difficult or sophisticated for lower level students to comprehend. Additionally, secondary mathematics teachers would benefit from learning some pedagogical techniques and activities that are specifically designed to make proofs more accessible to lower level students.

In addition, we suggest that professional development should be focused on helping teachers to reflect on their teaching philosophy and open the horizons for learning other trends and visions (e.g., absolutist and fallibilist philosophy of mathematics and mathematics education). Given the day-to-day demands of classroom teaching, it is easy to lose sight of the overarching purpose of educating children in mathematics, regardless whether we are preparing our students to have the content specific skills to be professional mathematicians or using mathematics as a vehicle to develop their thinking skills. We expect that given the opportunity many secondary mathematics teachers may realize that their every-day pedagogical decisions (with respect to proof) do not reflect their underlying teaching philosophies, which may be sufficient to promote changes we are recommending.

We encourage teacher educators, student advocates and professional organizations to acknowledge that reserving proof experiences from lower level students is a matter of great inequity in our schools. Teachers may not realize the implications of reserving proof from lower level students due in part to their own misconceptions about proofs, however, as a society we are surely letting much of our human potential go undeveloped by reserving opportunities to facilitate abstract reasoning abilities in lower level students, who need those abilities as much as anyone else in society.

Logic and deductive reasoning ability are emphasized in mathematics in ways that cannot be found in any other discipline. If mathematics education cannot offer opportunities to lower level students to acquire and expand their reasoning abilities, then where else would they develop these abilities?

\section{References}

Bloom, B. S., Engelhart, M. D., Furst, E. J., Hill, W. H., \& Krathwohl, D. R. (1956). Taxonomy of educational objectives: cognitive domain, McKay, New York, 1956.

$\begin{array}{lllll}\text { Center for } & \text { Mathematics } & \text { (CME) } & \text { Project }\end{array}$ http://www.phschool.com/webcodes10/index.cfm?fuseaction=home.gotoWebCode\&wcprefix=bek\&wcsuffix=0 099

Common Core State Standards Initiative. (2010). Common Core State Standards Initiative for mathematics. Retrieved from http://www.corestandards.org/assets/CCSSI_Math\%20Standards.pdf

Einstein, A. (n.d.). Albert Einstein Quotes. Retrieved from http://www.brainyquote.com/quotes/authors/a/albert_einstein.html

Frasier, B. J. (2010). Secondary school mathematics teachers' conceptions of proof. (Unpublished doctoral dissertation). University of Massachusetts Lowell, USA.

Goetting, M. M. (1995). The college students' understanding of mathematical proof. (Unpublished doctoral dissertation). University of Maryland, USA. 
Horn, J. L., \& Cattell, R. B. (1966). Refinement and test of the theory of fluid and crystallized general intelligences. Journal of Educational Psychology, 57(5), 253-270. http://dx.doi.org/10.1037/h0023816

Harel, G., \& Sowder, S. (1998). Students proof schemes: Results from exploratory studies. In A. Schoenfeld, J. Kaput, \& E. Dubinsky (Eds.), Research in collegiate mathematics education III, (pp. 234-283).

Jones, K. (1997). Student-teachers' conceptions of mathematical proof. Mathematics Education Review, 9, 16-23.

Kline, M. (1972). Mathematical thought from ancient to modern times. New York, Oxford University Press.

Knuth, E. (1999). The nature of secondary school mathematics teachers' conceptions of proof. (Unpublished doctoral dissertation). University of Colorado, USA.

Knuth, E. J. (2002). Teachers' conceptions of proof in the context of school mathematics. Journal of Mathematics Teacher Education, 5, 61-88. http://dx.doi.org/10.1023/A:1013838713648

Martin, W.G., \& Harel, G. (1989). Proof frames of pre-service elementary teachers. Journal for Research in Mathematics Education, 20(1), 41-51. http://dx.doi.org/10.2307/749097

National Council of Teachers of Mathematics (NCTM). (2000). Principles and Standards for School Mathematics. Reston, VA: NCTM.

Nickerson, R. (1996). Reasoning. In R. Dillon \& R. Sternberg (Eds.), Cognition and instruction, (pp 343-373).

Perrin, J. R. (2009). Developing reasoning ability through proof in high school calculus. Mathematics Teacher, 102(5), 341-349.

Seldon, A., \& J. Seldon. (2003). Validations of proof considered as texts: Can undergraduates tell whether an argument proves a theorem? Journal for Research in Mathematics Education, 34(1), 4-36. http://dx.doi.org/10.2307/30034698

Simon, M.A., \& Blume. G.W. (1996). Justification in the mathematics classroom: A study of prospective elementary teachers. Journal of Mathematical Behavior, 15, 3-31. http://dx.doi.org/10.1016/S0732-3123(96)90036-X

Sowder, L., \& Harel G. (1998). Types of students’ justifications. Mathematics Teacher, 91(8), 670-675.

Stylianides, G. J., \& Stylianides. A. J. (2009). Facilitating the transition from empirical arguments to proof. Journal for Research in Mathematics Education, 40(3), 314-352.

Varghese, T. (2007). Student teachers' conceptions of mathematical proof. (Unpublished master's thesis). University of Alberta, Edmonton, Canada.

Wu, H. (1996). The role of Euclidean geometry in high school. Journal of Mathematical Behavior, 15, 221-237. http://dx.doi.org/10.1016/S0732-3123(96)90002-4 